\title{
Vertical Displacement Monitoring and Safety Evaluation of Oil Pipelines in Permafrost Region
}

\author{
Liangliang Li ${ }^{1}$, Hongyu $\mathrm{Ma}^{2}$, Hongyuan Jing ${ }^{3}$ \\ ${ }^{1}$ Petro China Pipeline R \& D Center, Langfang, China \\ ${ }^{2}$ Xi'an Oil \& Gas Transportation Company, Petro China Pipeline Company, Xi'an, China \\ ${ }^{3}$ Petro China Pipeline Company, Langfang, China \\ Email: kjlill@petrochina.com.cn,dlhyma@petrochina.com.cn, kjjhy@petrochina.com.cn
}

How to cite this paper: Li, L.L., Ma, H.Y. and Jing, H.Y. (2018) Vertical Displacement Monitoring and Safety Evaluation of Oil Pipelines in Permafrost Region. Journal of Geoscience and Environment Protection, 6, 247-256.

https://doi.org/10.4236/gep.2018.65021

Received: April 13, 2018

Accepted: May 28, 2018

Published: May 31, 2018

\begin{abstract}
This paper presents the development of a liquid pressure based automatic monitoring device of the vertical displacement of oil pipeline that has good applicability to the extreme cold conditions of the permafrost region and is capable of automatic collection and transmission of monitoring data. The effectiveness of the device has been verified using total station measurement method and the results show that the device can intuitively indicate the vertical displacement of the pipe under the harmful influence of frost heaving and thaw settlement. According to the monitoring data, safety evaluation of the pipe during the monitoring period is carried out using stress-based design criteria and strain-based design criteria respectively. The analytic results with stress-based design criteria show that the pipe may be in a dangerous state while the results with strain-based design criteria show that the pipe is in a safe state. The design method with strain-based criteria is complementary to the design method with stress-based criteria. Separate use of either method is not recommended.
\end{abstract}

\section{Keywords}

Frozen Soil, Pipelines, Monitoring, Safety Evaluation

\section{Introduction}

China-Russia crude oil Mohe-Daqing Pipeline is the first large-diameter oil pipeline laid in the high-cold frozen soil area in China. The extreme cold weather and complex geological environment in the permafrost region bring a series of new safety problems to pipeline operation, including the most prominently 
frost heaving and thaw settlement, which impose the biggest challenge to the safe operation of the pipeline [1]. Differential frost heaving and thaw settlement can lead to serious stress concentration on the pipe [2] and endanger pipeline safety. Obviously, it would be very wasteful to take engineering prevention and control measures on the entirety of the nearly 440 kilometers long section of pipeline that penetrate the frozen soil. It is therefore essential to take effective monitoring methods on the pipe or the frozen soil and then determine whether to carry out engineering prevention and control measures according to the monitoring results. After finding out the actual conditions of the cushion layer, the monitoring results of the vertical displacement of the pipe can intuitively indicate the safety status of pipeline and the development of frozen soil hazard.

\section{Monitoring Design}

\subsection{Monitoring Principle}

Existing monitoring technologies of buried pipeline displacement, such as mechanical displacement monitoring [3], GPS monitoring, etc., although mature, face difficulties in monitoring pipe displacement in the permafrost region because the region is often covered by ice and snow, has very low ambient temperature in winter, and tends to form swamp and mud pit in summer: 1) Low ambient temperature. The temperature, generally about $-20^{\circ} \mathrm{C}$, and sometimes as low as $-50^{\circ} \mathrm{C}$ in extreme weathers, imposes strict requirements on the cold resistance performance of the electronic equipment and the battery endurance in low temperature. Low temperature is also a detrimental factor for long term field data collection by manual means. 2) Inconvenience of field work. The region to be monitored is usually covered by ice and snow in winter, and mostly turns into swamp and mud pit in summer, causing inconvenience for field work; 3) Fire and theft prevention requirements. Most of the pipeline passes through fire prevention area of natural forest, which imposes fire prevention requirements for electronic equipment. Therefore, the monitoring device should be capable of automatic collection and transmission of displacement data of the pipe under the harsh natural environment of Mohe-Daqing Pipeline. In view of this, an automatic monitoring device for pipeline vertical displacement based on liquid pressure is developed.

The working principle of the monitoring device is as follows: Displacement sensors are installed on a reference pile (which is driven deep into the underground stable soil layer or bedrock and can be considered stationary) and monitoring piles (which are fixed on the pipe and move synchronously with the pipe); the differential hydraulic pressure of the sensors is then measured, and converted through some simple calculations to obtain the absolute displacement value of the pipe.

\subsection{Monitoring Layout}

The device consists of: 1) the monitoring assembly, which mainly consists of 
displacement sensors, monitoring piles, a reference pile, pipe clamps and the gas-liquid pipeline to realize the measurement function of the vertical displacement of the pipe; 2) the control assembly, which mainly consists of buried sealing box, RTU, battery and GPRS modules to realize the functions of data acquisition, control and transmission; and 3) the remote monitoring center, which mainly consists of server and processing software to realize the data processing and information release functions. The working principle and process flow are shown in Figure 1.

The monitoring device has exhibited good adaptability and operability under the extremely harsh environment of Mohe-Dalian pipeline and has the capability of unmanned automatic monitoring and long-distance transmission of data with a precision of $3.5 \mathrm{~mm}$ when the measuring range is $3.5 \mathrm{~m}$, which is sufficient for pipe displacement monitoring. An experimental monitoring site was established at the edge of the alluvial flat swamp $33 \mathrm{~km}$ from the Jiagedaqi-Mohe Highway in Jiagedaqi City, Heilongiiang Province. Geotechnical investigation results of the experimental site show that the swamp area comprises cohesive permafrost soil, the lithology of which is gravelly silty clay, with a frost heaving rate of IV, a frost heaving sensitivity of "very sensitive" and a thaw settlement sensitivity of "moderately very sensitive"; The area outside the swamp also comprises cohesive permafrost soil, the lithology of which is also gravelly silty clay, but with a frost heaving rate of I, a frost heaving sensitivity of "not sensitive" and a thaw settlement sensitivity of "slightly sensitive". Monitoring point \#A and the reference point are located on the outer edge of the swamp area; monitoring point \# $\mathrm{B}$ is located within the swamp area, as shown in Figure 2.

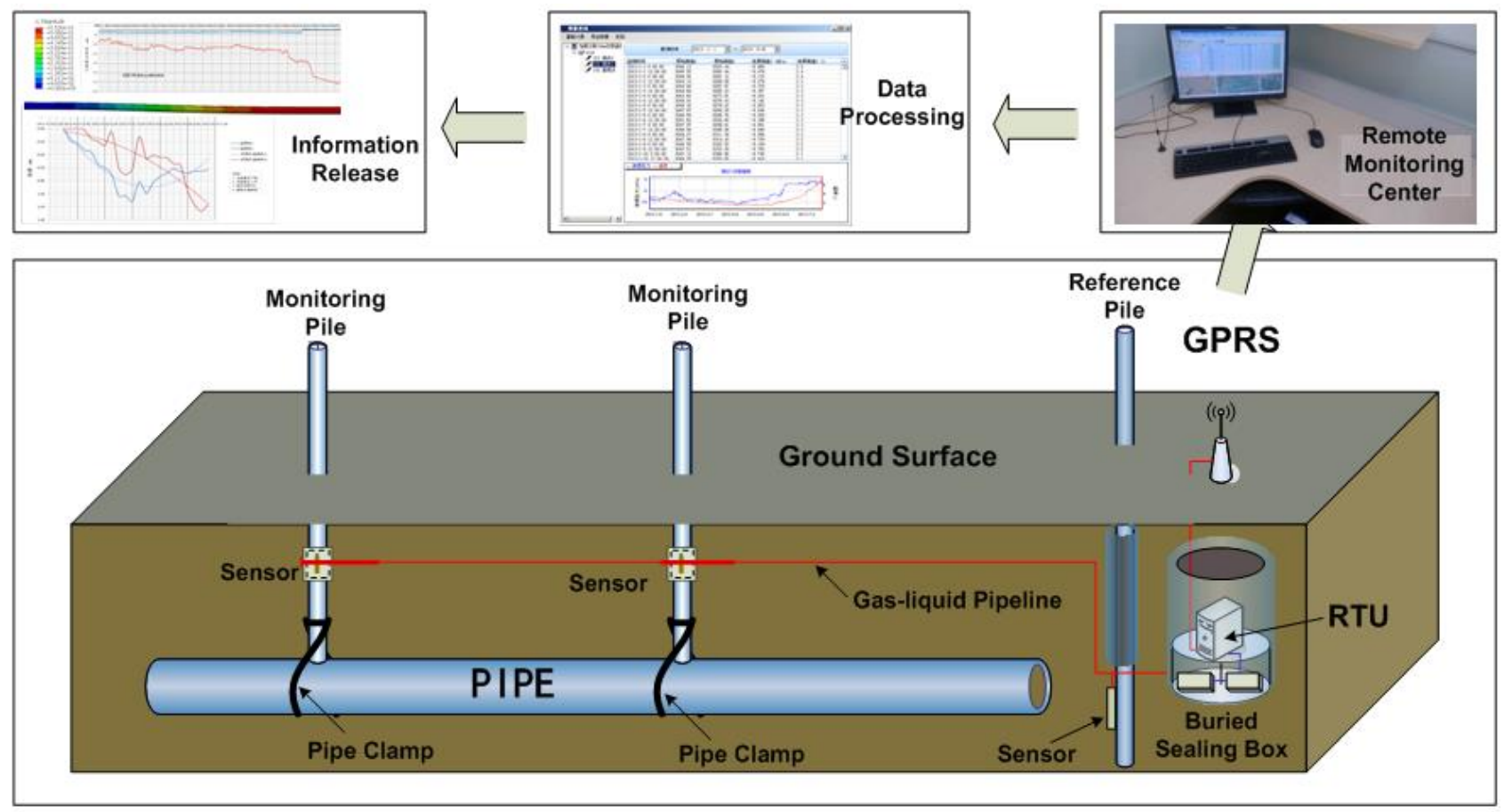

Figure 1. Working principle and process flow of monitoring device. 


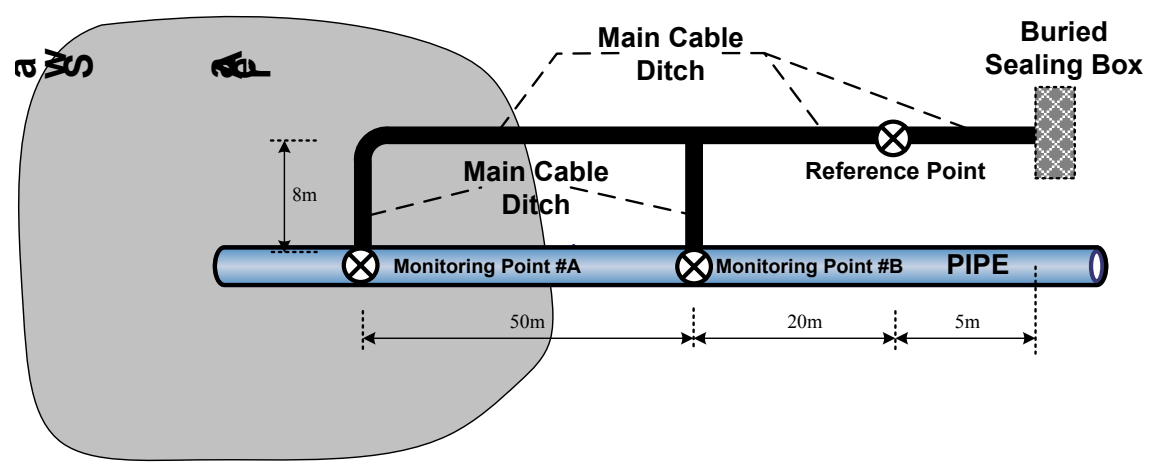

Figure 2. Schematic diagram of monitoring point layout

\section{Monitoring Verification}

\subsection{Data Processing}

The vertical displacement trend curves at the two monitoring points of the pipe were drawn according to the processed monitoring data of a 12-month period since the formal operation of the monitoring device (operation started in early October of the installation year), as shown in Figure 3. The following conclusions can be drawn from the figure: 1) During the whole monitoring period, the pipe at monitoring point \#A (outer edge of swamp area) can be considered as having remained in a temporarily stable state as it did not endure any obvious settlement or lifting and the fluctuation amplitude of vertical displacement is very small $(<5 \mathrm{~cm}) ; 2)$ The vertical displacement of the pipe at monitoring point \#B (near the center of the swamp) fluctuated greatly, with an overall continuous sinking trend, especially after entering middle May of the following year after installation, during which a significant maximum accumulated settlement of $54.63 \mathrm{~cm}$ was observed before transiting to a stable trend; 3 ) There is an obvious inflection point from settlement to heaving in the curve of monitoring point \#B in middle November of the installation year.

\subsection{Verification}

According to geological survey results, the stratum at monitoring point \#A located at the outer edge of the swamp area exhibited hardly any frost heaving and only slight thaw settlement. Therefore, the pipe at monitoring point \#A will not undergo any obvious settlement or heaving without interference of human engineering activities (such as manual mechanical operation) or natural factors (such as flood, snowstorm, catchment freezing, etc.), as can be concluded from the change trend curve of pipe displacement shown in Figure 3. According to geological survey results, the stratum at monitoring point \#B exhibited significant frost heaving and thaw settlement, so there is high possibility for occurrence of obvious settlement or heaving of pipe at monitoring point \#B. According to monitoring data, significant displacement fluctuations did occur at monitoring point $\# \mathrm{~B}$, as shown in Figure 3. In order to verify the effectiveness of the automatic monitoring device, a total station is used to measure the displacement 
at the top of the monitoring pile, i.e., the total station is placed at the top of the reference pile to measure the relative elevation of the top of the monitoring pile at different time points. The displacement value of the monitoring point can then be obtained by calculating the elevation difference (see document [3] for the specific working principle). The relative elevation of the top of the monitoring pile was measured at two time points, December 13 of the installation year and June 18 of the following year. The calculation results show that the elevation of monitoring point \#A rose by $0.73 \mathrm{~cm}$ and that of monitoring point \#B sunk by $33.84 \mathrm{~cm}$. These results are close to the displacement values monitored by the automatic monitoring device (monitoring point \#A rose by $1.92 \mathrm{~cm}$ and monitoring point \#B sunk by $29.86 \mathrm{~cm}$, as shown in Figure 3). The comparison is shown in Table 1. Thus, the automatic monitoring device can effectively indicate the change in the vertical displacement of the pipe.

It is noteworthy that monitoring point \#B underwent an obvious settlement/ heaving process in mid-November of the installation year, as shown in Figure 4. According to later investigation, this change was caused by the operator's backfilling activities at a subsidence pit near the monitoring point in early November

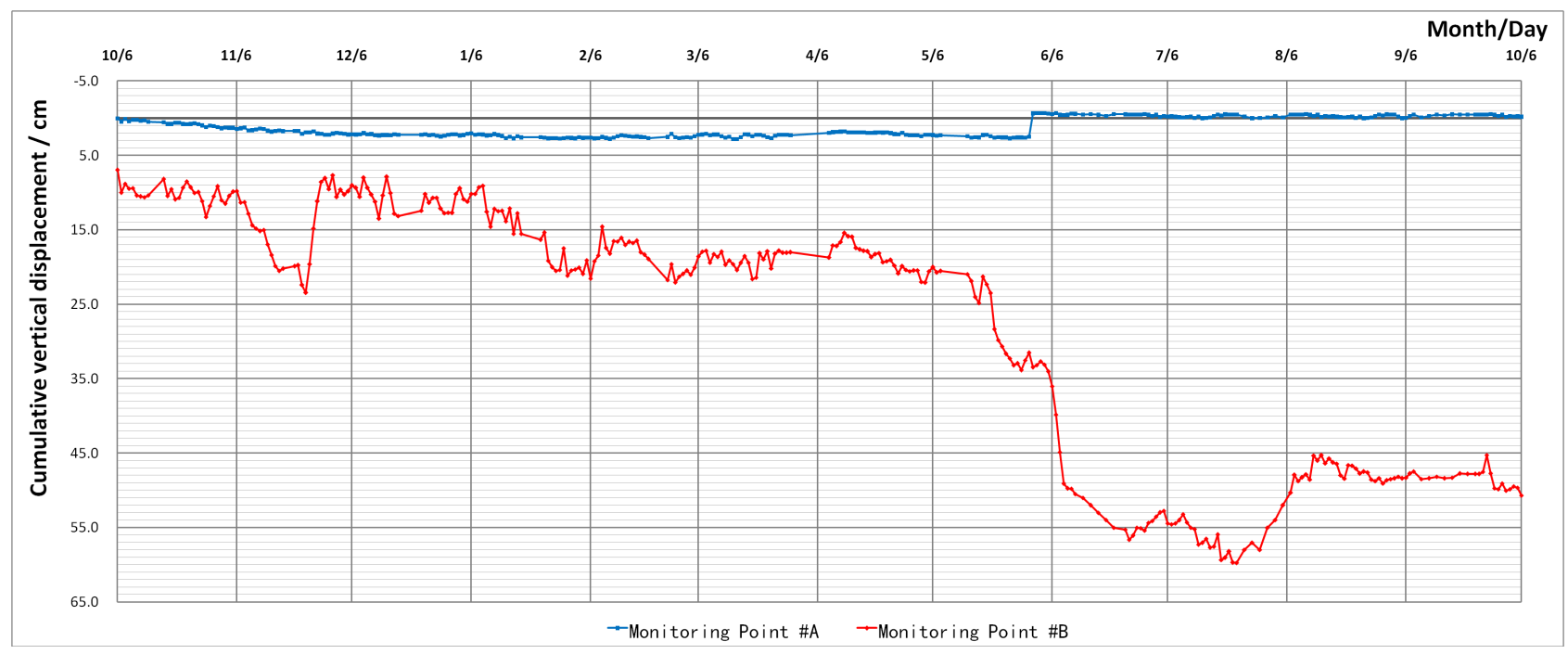

Figure 3. Trend curve of cumulative vertical displacement of pipe (positive value indicates settlement and negative value indicates heaving).

Table 1. Comparison of displacement values between automatic monitoring results and total station verification results

\begin{tabular}{ccccc}
\hline \multirow{2}{*}{$\begin{array}{c}\text { Monitoring } \\
\text { point }\end{array}$} & $\begin{array}{c}\text { Relative elevation/m } \\
\text { of installation year }\end{array}$ & $\begin{array}{c}\text { June 18 of the } \\
\text { following year }\end{array}$ & Total station & $\begin{array}{c}\text { Automatic } \\
\text { monitoring device }\end{array}$ \\
\cline { 2 - 5 } $\begin{array}{c}\text { Monitoring } \\
\text { point \#A }\end{array}$ & 99.5685 & 99.5758 & -0.73 & -1.92 \\
$\begin{array}{c}\text { Monitoring } \\
\text { point \#B }\end{array}$ & 99.4613 & 99.1229 & +33.84 & +29.86 \\
\hline
\end{tabular}

Note: In the displacement values, "-" indicates heaving and “+" indicates settlement. 


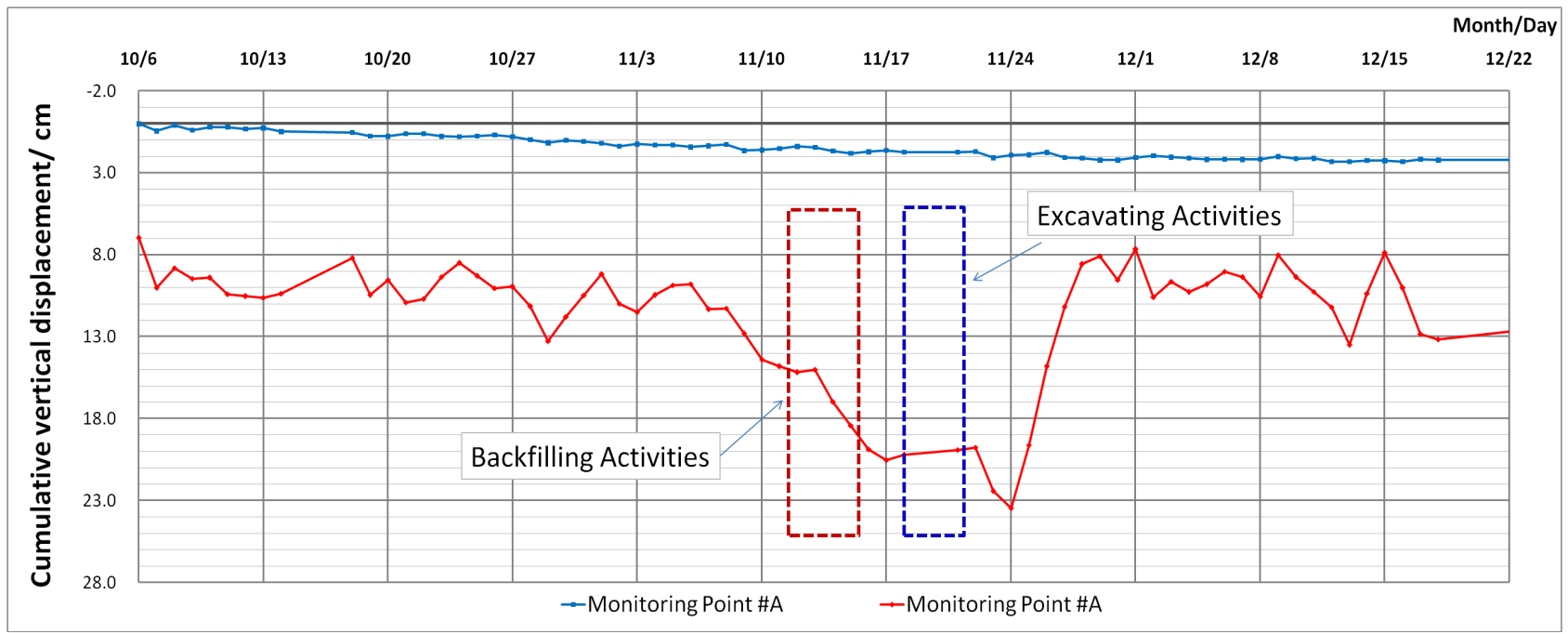

Figure 4. Pipe displacement caused by earthwork operation.

and subsequent partial leveling of the earthwork in mid-November because the backfilled earthwork caused excessive load. Gravity load of large quantity of backfilled earthwork caused the pipe at monitoring point \#B to rapidly settle; subsequent leveling in turn rapidly reduced the load on the pipe. Earthwork removal and pipe rebound together resulted in the up heaving. This proves that the monitoring system can accurately indicate the displacement of the pipeline.

\section{Pipe Safety Evaluation}

\subsection{Thaw Settlement Analysis}

Frost heave and thaw settlement are two common phenomena that occur to the soil around buried pipelines in the permafrost region, and greatly affect the construction of pipelines, causing frost damage to the project [4]. Frost heaving will generally cause soil uplift, and thaw settlement will cause soil subsidence. The pipe at monitoring point $\# \mathrm{~B}$ underwent obvious settlement, indicating that the soil layer in this area is mainly exposed to thaw settlement risks.

For Mohe-Daqing Pipeline, the main causal factor leading to the thawing of permafrost soil under the pipeline is heat dissipation of the oil transport pipeline. The warm transport pipeline will result in the formation of a thawed cylinder around it. Therefore, the pipeline foundation has little bearing capacity if the water (ice) content is high [5]. After many years of operation of China-Russia crude oil Mohe-Daqing Pipeline at an above-zero temperature, a thawed circle has formed around the pipeline and gradually increases. For sections with high ice content, consolidation settlement occurs after thawing of frozen soil, which has resulted in obvious surface subsidence and water accumulation. The pipeline and the surrounding soil are also sinking at the same time.

For pipe sections with soil-containing ice, ice-saturated frozen soil, or ice-rich frozen soil underneath, when the pipeline operating temperature is high (as is the current pipeline operating temperature), the pipeline temperature will lead 
thawing and subsidence of the frozen soil below, so that the pipeline loses support and sinks with it. In differential settlement displacement sections (transition from non-thaw settlement section to thaw settlement section, or from one thaw settlement section to another, or traversing multiple sections with greatly different settlement coefficients), the pipeline will endure uneven settlement, producing greater additional stress and strain. Meanwhile, the differential thaw settlement of the permafrost soil will impose uneven shear stress and strain on the pipeline, resulting in pipeline damage [5] and threatening pipe safety.

\subsection{Pipe Safety Evaluation}

The settlement coefficient and consolidation large deformation theory can be used to study the settlement deformation, and the elastic-plastic theory can be used to analyze the stress-strain behavior of pipeline and soil. However, due to the complexity of the calculation of stress and strain in differential thaw settlement sections of the pipeline, it is often difficult to obtain an accurate numerical solution using the numerical theoretical calculation method. Therefore, ABAQUS software is used to carry out simulation calculation of stress and strain of the pipeline under thaw settlement risks at the monitoring points. The simulated working condition is shown in Figure 5 (the total station measurement data or the automatic monitoring data, whichever is larger, is taken as the displacement data of the monitoring point). The modeling and processing process is omitted for conciseness in this paper.

Most of the existing pipeline design standards in China and abroad follow the traditional stress-based design criteria, which can provide a conservative guarantee for pipe safety. However, for pipeline design where displacement is the control factor of load action such as in the scenarios of earthquake, landslide and submarine pipeline laying, the stress-based strength design criteria are no longer applicable because the pipeline stress has exceeded the yield limit. Strain-based design is recommended for such cases [6] [7]. In this paper, the safety analysis of the pipeline is carried out using both stress-based design criteria and strain-based design criteria respectively. The results are for reference only.

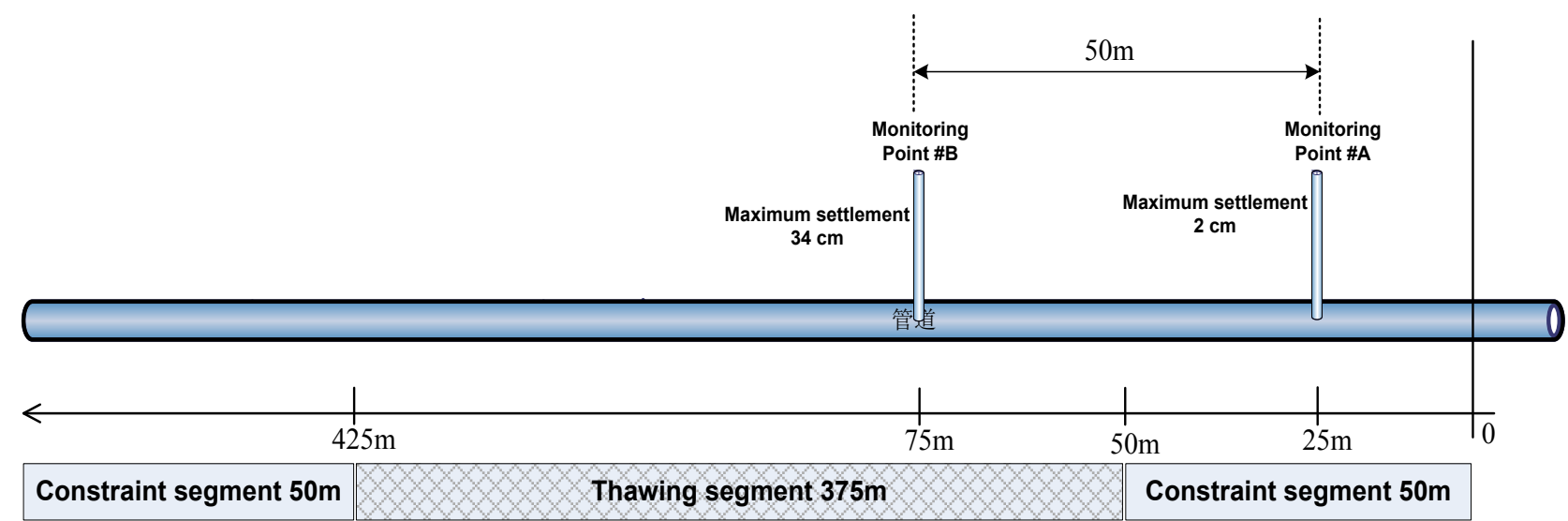

Figure 5. Schematic diagram of simulated working condition. 
Mohe-Daqing Crude Oil Pipeline is made of X65 material. If defect-free, the material has minimum yield strength of $450 \mathrm{MPa}$. The allowable stress is 0.72 times of the minimum yield strength [8], i.e., $324 \mathrm{MPa}$. The limit tensile strain of the pipe is 0.053 and the allowable tensile strain is 0.7 times of the limit tensile strain [9], i.e., 0.0371. Figure 6 and Figure 7 respectively show the numerical simulation curves of stress and strain of the pipe against pipe length.

As can be seen from Figure 6 and Figure 7, both the stress and strain hazard points of the pipeline are located between monitoring point \# A and monitoring point \#B, and are $22.32 \mathrm{~m}$ away from monitoring point \# $\mathrm{A}$. The maximum stress on the pipeline is $366.7 \mathrm{MPa}$, which is $324 \mathrm{MPa}$ in excess of the allowable stress. The pipeline would be in unsafe state taking the allowable stress as the judgment criterion. But the maximum strain of the pipeline is 0.00171 , which is far less than the allowable tensile strain of 0.0371 . The pipe is in a safe state taking the allowable strain as the judgment criterion.

It is noteworthy that the stress-based design method is suitable for elastic

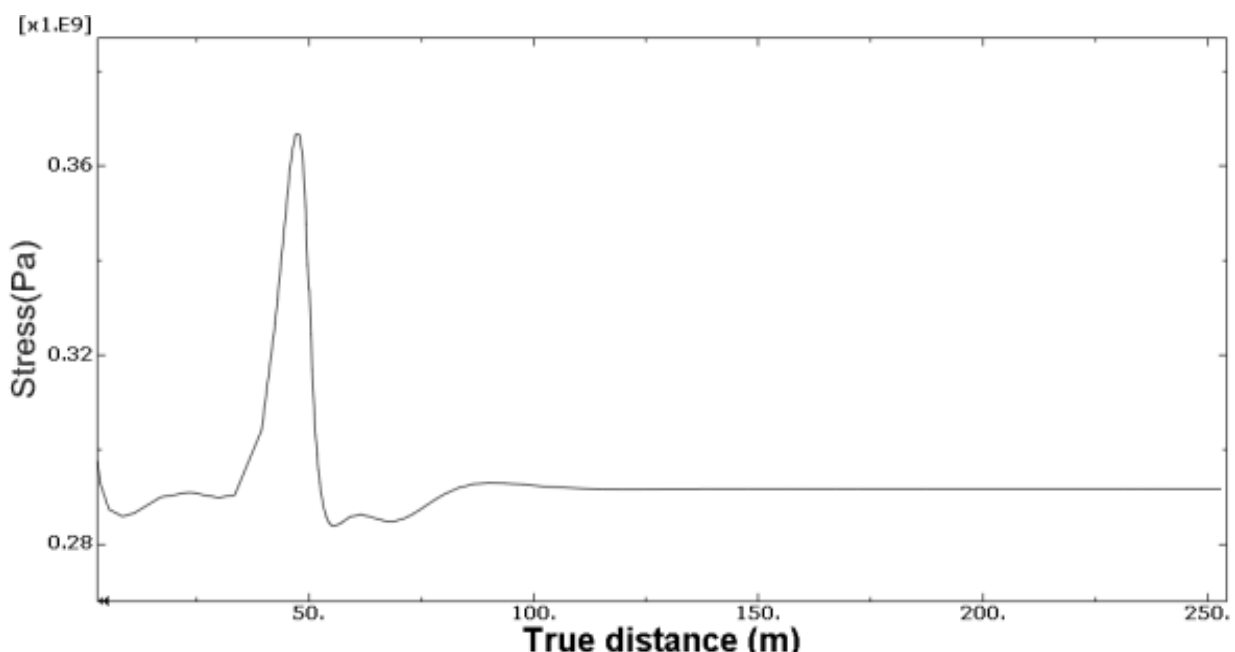

Figure 6. Stress distribution along pipeline.

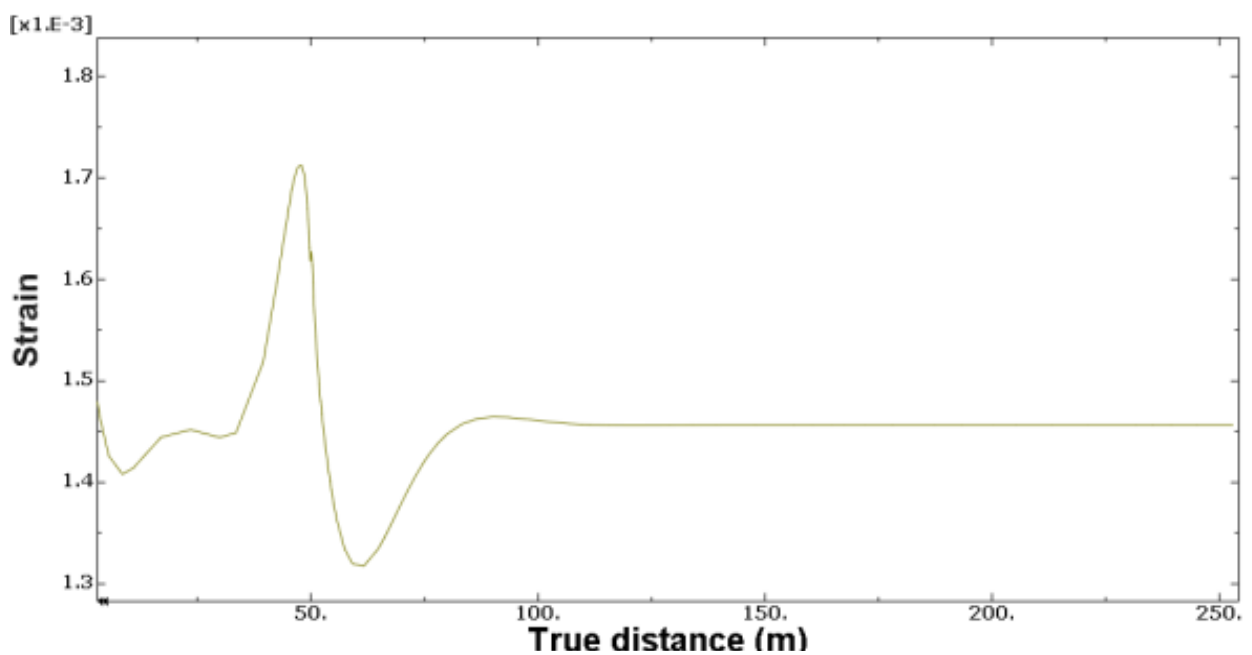

Figure 7. Strain distribution along pipeline. 
design under the action of load with internal pressure and temperature difference as control parameters. The strain-based design method on the other hand is suitable for plastic design, which is generally applicable to the load acting on the pipeline in the event of a major geological disaster, with displacement as a control parameter. It is supplementary to the stress-based design method. For safety evaluation of pipeline in the extremely cold permafrost region, it is suitable to adopt the strain-based design criteria while taking the stress-based design criteria as a supplement, except where internal pressure and temperature difference are the control parameters of load action, in which case the stress-based design criteria should be used solely.

\section{Conclusions}

1) The liquid pressure based automatic monitoring device of oil pipeline vertical displacement has good adaptability and operability under the extremely harsh environment of Mohe-Daqing Pipeline. The device is capable of unmanned automatic monitoring and remote data transmission and can intuitively indicate the vertical displacement of the pipe exposed to frost heaving and thaw settlement hazards.

2) Considering the Mohe-Daqing Pipeline operates at above-zero temperature all the year round, the main threat facing the pipeline is the uneven settlement of the pipe caused by thaw settlement.

3) For safety evaluation of pipeline in the extremely cold permafrost region, it is suitable to adopt the strain-based design criteria while taking the stress-based design criteria as a supplement, except where internal pressure and temperature difference are the control parameters of load action, in which case the stress-based design criteria should be used solely.

\section{References}

[1] Liu, J.J. and Xie, J. (2013) Nmuerical Simulation of Thermo-Hydro-Mechanical Coupling around Underground Pipelines in Patchy Permafrost Region. Rock and Soil Mechanics, 34, 444-449.

[2] Lv, H.Q., Pu, X.B., et al. (2010) Technique of Pipeline Design in Permafrost Zones. Journal of Logistical Engneering University, 26, 25-28.

[3] Tan, D.J., Zheng, J., et al. (2012) Displacement Monitoring of Mohe-Daqing Oil Pipeline in the Permafrost Area. Oil \& Gas Storage and Transportation, 31, 737-739.

[4] Yang, T., Ma, G.Y., et al. (2009) The Effect of the Frost Heave and Thawing Settlement on Oil Pipeline in Frozen Soil Region. Pipeline Technique and Equipment, No. $4,40-43$

[5] Jin, H.J., Yu, W.B., et al. (2005) (Differential) Frost Heave and Thaw Settlement in the Engineering Design and Construction of Oil Pipeline in Permafrost Regions: A Review. Journal of Glaciology and Geocryology, 27, 456-458.

[6] Liu, B., Liu, X.J., et al. (2008) Pipeline Design Criteria Based on Strain and the Control Factors. Journal of Southwest Petroleum University (Science \& Technology Edition), 34, 143-147.

[7] Pan, J.H. (2005) Several Concernment Task under Development of High Strength 
Pipeline Steel. Welded Pipe and Tube, 28, 1-2.

[8] GB50253-2003 (2006) Code for Design of Oil Transportation Pipeline Engineering. China Plans to Press.

[9] GB50470-2008 (2009) Seismic Technical Code for Oil and Gas Transmission Pipeline Engineering. China Plans to Press. 